\title{
POLÍTICA EXTERNA COMO POLÍTICA PÚBLICA: UMAANÁLISE PELA REGULAMENTAÇÃO CONSTITUCIONAL BRASILEIRA (1967-1988)
}

\author{
Michelle Ratton \\ Sanchez
}

\author{
Elaini C. G. da \\ Silva
}

\author{
Evorah L. \\ Cardoso
}

\author{
Priscila \\ Spécie
}

\begin{abstract}
RESUMO
O objetivo deste trabalho é relacionar os debates sobre politica externa e politica pública, a partir de uma perspectiva constitucional. Para afastar o consenso de que a política externa sempre foi considerada como "externa" aos estados e distinta de toda e qualquer política doméstica - e assim de toda e qualquer política pública -, buscou-se identificar as políticas interna, externa e internacional como um continuum de um mesmo processo decisório. A partir desses pressupostos teóricos, apresentou-se uma análise da distribuição de competências da política externa brasileira nas constituições de 1967 e 1988, com o intuito de identificar, no contexto de redemocratização do Brasil possiveis alterações na regulamentação da política externa que sugerissem a incorporação de uma concepção de gestão poliárquica, que a aproximasse das demais políticas públicas. Por fim, compararam-se os mecanismos disponíveis na Constituição de 1988 para o controle da política externa e das políticas públicas em geral, a fim de proceder-se à sua aproximação e verificar a aplicabilidade dos mecanismos relativos às políticas públicas para controle da política externa.
\end{abstract}

PALAVRAS-CHAVE: política externa; políticas públicas; regulamentação constitucional; Constituição federal de 1967; Constituição federal de 1988; redemocratização brasileira.

\section{POLÍTICA EXTERNA COMO POLÍTICA PÚ- BLICA?}

O leitor pode questionar-se se a identificação entre política externa e política pública, em um primeiro momento, não é uma antinomia per se. A principal justificativa para essa desconfiança está no fato de que a política externa sempre foi considerada como "externa" aos Estados e distinta de toda e qualquer política doméstica ${ }^{2}$. Aliada a essa primeira questão está a concepção corrente de que apenas as políticas domésticas seriam considera-

\footnotetext{
${ }^{1}$ Agradecemos aos comentários apresentados por Miriam Dolhnikoff e Eduardo Marques à primeira versão deste texto, sem que qualquer responsabilidade por incorreções ou incoerências possa ser-lhes atribuída.

2 Tal concepção da política externa, apartada das demais políticas do Estado, é amplamente aceita no campo das Relações Internacionais em decorrência da forte influência da teoria realista, para a qual a política externa assume uma especificidade em relação às demais políticas internas, o que a impede de ser considerada também uma política pública; cf. por exemplo, Aron (2002, p. 127-152); diferentemente, ver Lima (2002).
}

das "políticas públicas", ou seja, respostas do Estado a situações socialmente problematizadas ${ }^{3}$.

A fim de enfrentar esses impasses, a análise deste artigo toma em consideração dois pressupostos: (i) as políticas interna, externa e internacional compõem um continuum de processo decisório e (ii) a política externa não se diferencia das demais políticas públicas. Esses pressupostos apóiam um ao outro de forma a permitir a reconcepção do processo decisório da política externa sob os referenciais da política pública.

$\mathrm{O}$ primeiro pressuposto parte do reconhecimento, mesmo por autores que adotaram uma visão mais restrita do conceito de política externa, a exemplo de Marcel Merle ${ }^{4}$, de que há grandes desafios no isolamento da política externa como uma política distinta e com autonomia em relação às demais, quando se considera a intensificação

\footnotetext{
3 Ver, por exemplo, Muller (1990) e Bucci (2002).

4 Merle (1998, p. 205) considerava-a um instrumento de ação exterior do Estado, com base nos interesses e valores territorialmente situados.
} 
dos fluxos de interação entre os ambientes interno e internacional ${ }^{5}$. O que se toma como desafio nesta seção do artigo é pontuar, portanto, alguns elementos que evidenciam mudanças nesse isolamento e desafiam a concepção diferenciada da política externa.

Em recentes discursos, autoridades que coordenam a política externa brasileira reforçam o fato de encontrarmo-nos em um "mundo interdependente"6. Nesse contexto, o Presidente Luís Inácio Lula da Silva e o Primeiro Ministro britânico, Tony Blair, em discurso conjunto publicado em março de 2006, situaram a iniciativa da "governança progressista": "Nosso encontro deixou, uma vez mais, claro que a governança progressista não se limita a uma reflexão sobre a política interna de nossos países. Ela também implica uma abordagem comum dos desafios internacionais" (LULA DA SILVA \& BLAIR, 2006, p. A3; sem grifos no original).

Tais discursos políticos evidenciam as interrelações entre as políticas interna, externa e internacional. Uma base teórica que avançou neste diagnóstico foi a da "interdependência", desenvolvida por Robert Keohane e Joseph Nye em fins da década de $1970^{7}$. Essa teoria remete a uma determinada concepção de mundo em que é reforçada a relevância das diversas relações políticas e sociais entre Estados e outros atores de caráter não estatal, na condução da política internacional ${ }^{8}$. Uma pergunta que recai sobre essa concepção é: quais

5 Merle (1998 p. 46) reconhece essa interação ao apontar que "Beaucoup des problèmes internes ont été 'internationalisés', en même temps que beaucoup des problèmes internationaux ont été 'internalisés"' ["muitos problemas internos foram 'internacionalizados', ao mesmo tempo que vários problemas internacionais foram "internalizados"” - nota do editor].

6 Destacam-se, nesse sentido, os discursos do Presidente Luis Inácio Lula da Silva e do Ministro de Relações Exteriores do Brasil, Celso Luiz Nunes Amorim, disponíveis no portal eletrônico do Ministério das Relações Exteriores (http://www.mre.gov.br/). Discursos com a aplicação da mesma terminologia também podem ser encontrados em períodos anteriores de presidentes da República e de ministros das Relações Exteriores do Brasil.

7 Especialmente a partir de Keohane e Nye (2000a). Para algumas revisões e atualizações do conceito de interdependência, ver Keohane e Nye (2000b, p. 104-119).

${ }^{8}$ A base da teoria da interdependência tem sido apropriada no Brasil não apenas pelo discurso político, mas também são os mecanismos para a coordenação da interdependência entre os Estados e, sobretudo, na coordenação das políticas interna e internacional? Outra, relacionada à primeira, é: em que medida a "interdependência" afeta o processo decisório político, dentro e fora dos Estados? Essa última é a que interessa na análise a ser desenvolvida neste artigo.

Helen Milner (1997), em sua obra Interest, Institutions and Information, traz uma proposta sobre como repensar essas perguntas. Para tanto, a autora elenca momentos da produção teórica que abordam a relação entre as políticas interna, externa e internacional ${ }^{9} \mathrm{e}$, a partir da metodologia dos jogos de dois níveis de Robert Putnam, procura incorporar a este modelo o papel de outros atores além dos Estados. A partir dessa revisão, Helen Milner sugere que os processos decisórios, estruturados como poliarquias, formam um continuum - do nacional ao internacional ${ }^{10}$.

em outras formas de manifestação. Algumas dessas manifestações têm sido apresentadas de forma incompleta e não necessariamente coerente com o conceito tal como enunciado por Keohane e Nye (v. nota de rodapé 7). Nesse sentido, ver, a resenha crítica do livro "A identidade internacional do Brasil e a política externa brasileira", de Celso Lafer, escrita por Lacerda (2001). Nessa resenha, o autor indica a apreciação do conceito de "interdependência" por Lafer, sob uma perspectiva da coordenação única e restrita da política externa ao Estado. No mesmo sentido, pode-se suspeitar de que a apropriação de maneira incoerente também ocorre no discurso político; contudo, para este artigo, fica válida a indicação nessas manifestações de um reconhecimento da inter-relação entre as políticas.

9 De acordo com Milner (1997, p. 3ss.), em um primeiro momento (décadas de 1960 e 1970), a política externa dos estados era vista como um resultado da política interna. Em seguida (décadas de 1970 e 1980), houve a revisão dessa concepção, que passou a dar destaque para as influências internacionais no interno e vice-versa. Por fim (19801990), sob a influência dessas teorias, Robert Putnam sistematizou a teoria dos jogos de dois níveis. Tais referências teóricas apontadas por Milner também encontram reflexos na produção acadêmica brasileira quanto à concepção de política externa. A título de exemplo, podemos indicar, respectivamente, para o primeiro e o segundo momentos, Lafer (2004) e Fonseca Júnior (2004, p. 356).

10 "Most politics - both domestic and international however, lie in between this two poles in an area I call polyarchy, a structure more complex than either anarchy or hierarchy in which relations are shaped more like a network. No single group sits at the top; power or authority over decision making is shared, often unequally. Relations among groups in polyarchy entail reciprocal influence and/or the 
Relaciona-se aqui a abertura apresentada pelo discurso político brasileiro (sob a perspectiva multidimensional do conceito de interdependência) à proposta de Helen Milner (os processos decisórios como um continuum).

Além dessa concepção normativa sobre as políticas interna, externa e internacional, análises recentes da Ciência Política propõem-se a relacionar política externa com política pública ${ }^{11}$. Dentre os principais fundamentos para estabelecer essa relação, estão: de um lado, a política externa que, devido às mudanças no caráter da regulamentação internacional, cada vez mais, conecta-se ou confunde-se com políticas de caráter distributivo, redistributivo e regulatório ${ }^{12}$; de outro, a estrutura decisória necessária em Estados democráti-

parceling out of distinct powers among groups. My central claim is that state are not unitary actors; that is, they are not strictly hierarchical but are polyarchic, composed of actors with varying preferences who share power over decision making. [...] The search for international compromise becomes crucial in polyarchy. International politics and foreign policy become part of the domestic struggle for power and the search for international compromise. Domestic politics, then, varies along a continuum from hierarchy to anarchy, with polyarchy in between" (MILNER, 1997, p. 11) [“Muitos políticos tanto domésticos quanto internacionais -, todavia, ficam entre esses dois pólos em uma área que chamo de poliarquia, uma estrutura mais comlexa que tanto a anarquia quanto a hierarquia, em que as relação são modeladas mais como uma rede. Nenhum grupo individual fica no topo; o poder sobre ou a autoridade pela produção de decisões é compartilhada, freqüentemente de modo desigual. As relações entre grupos na poliarquia acarretam relações recíprocas e/ou a divisão de distintos poderes entre os grupos. Meu argumento central é que os estados não são atores unitários, isto é, eles não são estritamente hierárquicos mas são poliárquicos, compostos por atores com preferências variáveis e que compartilham o poder na tomada de decisão. [...] A busca de comprometimento internacional torna-se crucial na poliarquia. A política internacional e a política externa tornam-se parte da disputa doméstica pelo poder e pela busca de comprometimento internacional. A política doméstica, então, varia ao longo de um continuum, da hierarquia até a anarquia, com a poliarquia no meio"-N. E.].

11 Ver, por exemplo, Ingram e Fiederlein (1988 p. 725 745), Lima (2000, p. 283) e Lentner (2006).

$12 \mathrm{~V}$ er, por exemplo, Ingram e Fiederlein (1988 p. 726730) e Lentner (2006), com destaque para o quadro analítico apresentado na p. 730 de Ingram e Fiederlein. As autoras ainda indicam uma quarta categoria de políticas públicas apresentada por Theodore Lowi: "constituent policy" ("política constitutiva"). $\cos ^{13}$. Relacionar ambas as concepções normativas (continuum e política pública) permite que se desenvolva uma nova abordagem dos processos decisórios, que agora estão ainda mais plurais e complexos ${ }^{14} \mathrm{e}$ não mais circunscritos a tipologias pré-definidas (política interna distinta de política externa e da internacional). A nova abordagem indica que esses processos decisórios podem estar sujeitos a uma mesma metodologia de análise - que, neste artigo, remete às fases das políticas públicas ${ }^{15}$.

Neste trabalho, serão identificadas as seguintes fases de uma política pública: formulação, decisão, implementação e avaliação ${ }^{16}$. Tal metodologia será aplicada para a análise da regulamentação constitucional da distribuição de competências e formas de controle dos momentos tradicionalmente enquadrados sob a tipologia de política externa ${ }^{17}$.

\footnotetext{
13 Nesse sentido, especificamente, ver Ingram e Fiederlein (1988, p. 726) e Lima (2000, p. 283).

14 Mais plurais no sentido da poliarquia de Helen Milner, isto é, são muitos outros momentos decisórios que se estruturam conforme os atores (estatais e não estatais) envolvidos. E complexos no sentido de que os elementos que tradicionalmente constavam de uma ou outra política volatizam-se e compõem processos "mistos" (elementos anteriormente típicos da política doméstica confundem-se com os da política externa e da política internacional).
}

15 Quando a política externa é identificada como algo diverso da política interna e da política internacional - tal como tradicionalmente o foi - não parece ser possível apropriar-se dessa metodologia sem que haja uma revisão de seus conceitos. Entende-se aqui que, a partir do momento em que se define um continuum do processo de decisão, sob uma estrutura poliárquica tal como em Milner, é possível trazer a metodologia da política pública para um novo campo, mais amplo e não diverso. Abordagem que também se aproxima dessa metodologia é a de Lima (2002).

16 As fases das políticas públicas são definidas diferentemente por diversos autores. A definição mais relevante para este trabalho é a apresentada por Vargas (1992, p. 47), que identifica as seguintes etapas: (i) formação, (ii) formulação, (iii) implementação, (iv) avaliação, (v) análise e (vi) reformulação. Observa-se que, neste artigo, o que Vargas considera formulação foi subdividido em formulação e decisão. Além de Vargas, citamos como exemplos: Bucci (2002, p. 266), que considera as fases de formação, execução e avaliação, e Muller (1990, p. 28ss.), que define como essenciais apenas os momentos da tomada de decisão e da implementação.

17 Para Couto (2005, p. 95-97), há três dimensões da política: política constitucional ("polity"), política competitiva ("politics") e políticas públicas ("policy"). Neste ar- 
Observa-se que a expressão "política externa" é aqui empregada instrumentalmente para designar aqueles momentos de decisão tradicionalmente circunscritos à tipologia de política externa, ainda que defendamos a concepção de política externa como política pública e a idéia de continuum entre as políticas (interna, externa e internacional). Com isso, pretende-se permitir um recorte de momentos de decisão para análise e eventuais críticas e revisão da regulamentação de seus momentos, com base nos pressupostos normativos aqui apresentados.

O ponto de partida para a análise da regulamentação da distribuição de competências e de alguns meios de controle é a Constituição Federal de 1988 (CF-1988), por se constituir num marco regulatório do processo de (re)democratização no Brasil. No que tange a análise da regulamentação da distribuição de competências, serão comparados dois períodos relevantes e contrastantes da política nacional: o período militar (sob a égide da Constituição de 1967) e o pós-1988. Pretende-se com a análise desses dois períodos constitucionais observar se houve mudança significativa na regulamentação da política externa, da Constituição Federal de 1967 (CF-1967) - imposta com o objetivo de institucionalizar o regime de ditadura militar -, para a Constituição de 1988 - carta promulgada por uma Assembléia Constituinte, para restabelecimento do regime democrático.

Ademais, enquanto a análise da regulamentação das competências restringe-se àquelas relativas à política externa, na seção seguinte, procede-se à comparação dos meios de controle disponíveis sobre a política externa e as demais políticas públicas na própria Constituição de 1988.

Será verificado, assim, em que medida os processos decisórios da política externa em nível constitucional foram afetados por uma concepção poliárquica (que pressupõe, aqui, a concepção de política externa como uma política pública) e podem ser avaliados sob a metodologia desenvolvida para as fases das políticas públicas.

Para desenvolver essa análise, o artigo será estruturado em três partes, além desta introdução: o item II, em que se analisa comparativamente a distribuição de competências para a con- dução da política externa, nas Constituições de 1967 e 1988; o item III, em que se comparam os mecanismos de controle disponíveis para a política externa e outras políticas públicas, na Constituição de 1988, e a conclusão.

\section{ANÁLISE CONSTITUCIONAL DA DISTRI- BUIÇÃO DE COMPETÊNCIAS EM CONDU- ÇÃO DA POLÍTICA EXTERNA (1967-1988)}

A partir de uma pesquisa prévia sobre a regulamentação constitucional da política externa no Brasil, observou-se que, tradicionalmente, a condução da política externa é concentrada no poder Executivo ${ }^{18}$.

O mapeamento da regulamentação constitucional (1967-1988) foi sistematizado segundo os temas pertinentes à política externa recorrentemente regulamentados pelas constituições brasileiras, quais sejam: celebrar tratados; declarar guerra e celebrar a paz; e manter relações com outros Estados e participar de organizações internacionais ${ }^{19}$. Reforça-se que, sobre estes eixos temáticos, a metodologia das fases das políticas públicas será aplicada como critério de avaliação.

A partir do emprego desta metodologia, no quadro abaixo, evidencia-se como se dá a distribuição de competências entre os poderes Executivo, Legislativo e Judiciário na condução da política externa.

tigo, é feita a análise da distribuição constitucional de competências, ou seja, da polity, porque ela define o conteúdo legítimo e o processo decisório das políticas públicas. Notase, contudo, que, diferentemente de Cláudio Couto, entende-se que a regulamentação, constitucional ou infraconstitucional, também pode ser considerada elemento das políticas públicas (policy).

18 Tal assertiva é possibilitada a partir das conclusões de uma pesquisa que fez o levantamento das competências relativas à política externa nas constituições brasileiras desde 1824 até a presente (1988), cujo relatório intitula-se Politica externa como política pública: uma análise pela regulamentação constitucional brasileira (2006).

19 O mapeamento desses e de outros temas, como fronteiras nacionais e comércio internacional, foi realizado no trabalho referido na nota de rodapé 22; porém, não são aqui abordados porque não constam das Constituições Federais de 1967 e 1988. 

QUADRO 1 - DISTRIBUIČ̃̃O CONSTITUCIONAL DE COMPETÊNCIAS NA CONDUÇÃO DA POLÍTICA
EXTERNA 20

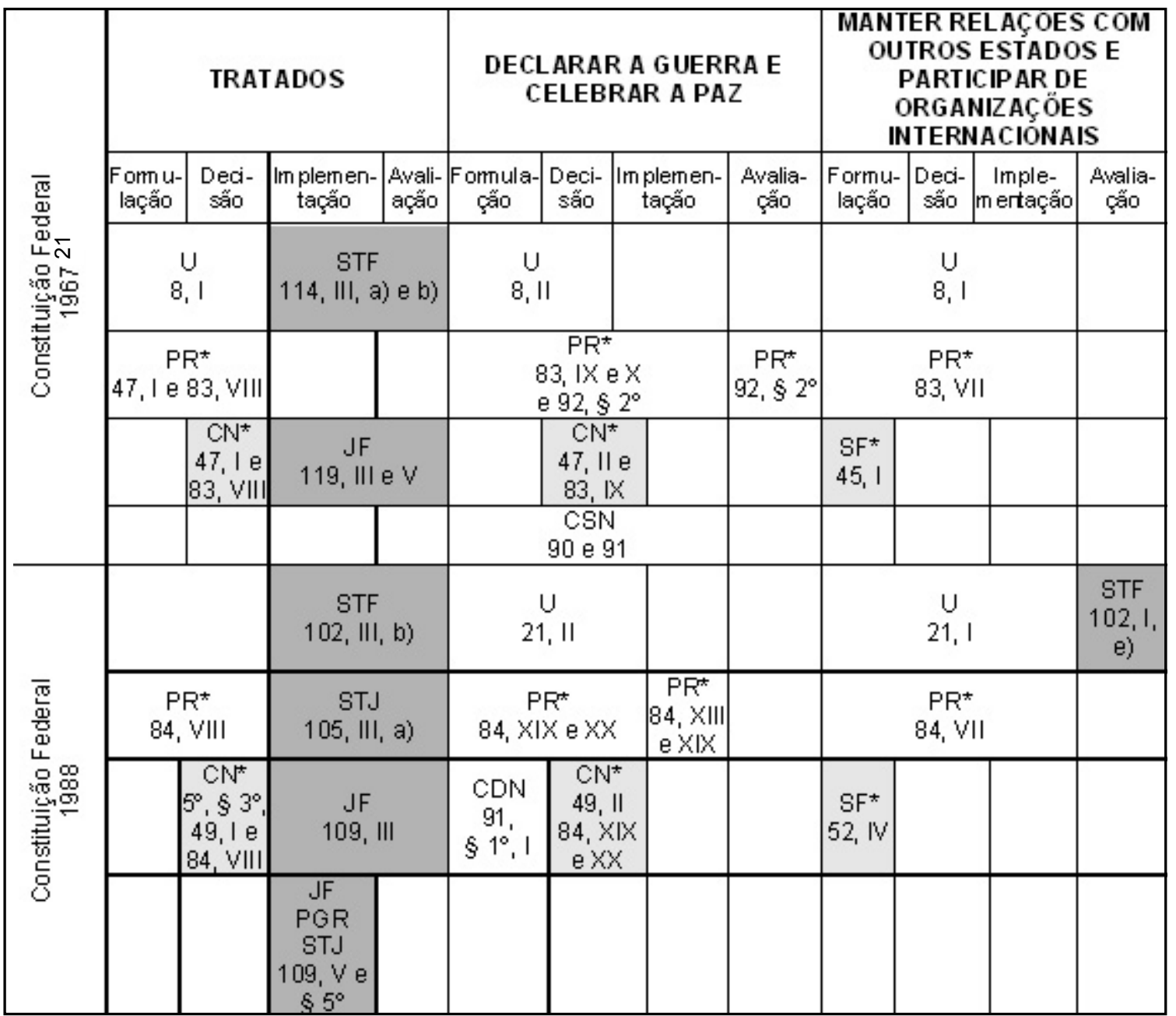

Fonte: as autoras.

NOTAS:

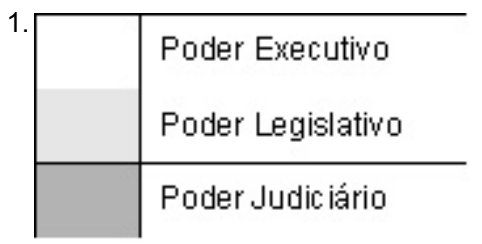

2. * = competência privativa ou competência exclusiva

3. U: União; PR: Presidente da República; CN: Congresso Nacional; SF: Senado Federal; STF: Supremo Tribunal Federal; STJ: Superior Tribunal de Justiça; JF: Justiça Federal; PGR: Procurador Geral da República; CSN: Conselho de Segurança Nacional; CDN: Conselho Nacional de Defesa.

A partir do quadro, observa-se que as Constituições de 1967 e 1988 não designam literalmente

20 Para acesso à íntegra dos dispositivos constitucionais, ver o Anexo.

21 As alterações da Emenda Constitucional n. 1 de 1969 relativas à política externa não são consideradas neste quadro porque não implicaram mudanças significativas na re- o poder competente para a formulação da política externa brasileira ${ }^{22}$, embora possuam dispositivos que distribuem a competência para sua condução entre os três poderes.

$\overline{\text { dação dos dispositivos alterados. Para efeitos de informa- }}$ ção, no Anexo, foram identificadas as alterações.

22 Diferentemente, as Constituições de 1937 (art. 73) e a Emenda Constitucional n. 4/1961 (art. 18) determinaram 
No que se refere ao poder Executivo, competem à União, na figura do Presidente da República, manter relações com estados estrangeiros e participar de organizações internacionais (arts. 21, I, e 84, VII, da CF-1988; arts. $8^{\circ}$, I, e 83, VII, da CF-1967); ao Presidente, privativamente, celebrar tratados e acordos internacionais (art. 84, VIII, da CF-1988; art. 83, VIII, CF-1967) e à União, na figura do Presidente da República, declarar a guerra $^{23}$ e celebrar a paz (arts. 21, II, e 84, XIX e XX, da CF-1988; arts. $8^{\circ}$, II, e 83 , IX e X, da CF-1967) ${ }^{24}$.

As competências do poder Legislativo estão presentes na atuação do Congresso Nacional sobre questões de política externa. Compete-lhe: resolver definitivamente sobre tratados, acordos ou atos internacionais (art. 47, I, da CF-1967)

expressamente a competência para dirigir e orientar a política externa, seja pelo Presidente da República (1937), seja pelo Presidente do Conselho de Ministros (1961). Sob a vigência da Constituição de 1988, identifica-se, na regulamentação infraconstitucional (Decreto n. 5 032/2004), que "cabe ao Ministério [das Relações Exteriores] auxiliar o Presidente da República na formulação da política exterior do Brasil, assegurar sua execução e manter relações com estados estrangeiros, organismos e organizações internacionais" (BRASIL. PRESIDÊNCIA DA REPÚBLICA. CASA CIVIL, 2004a, art. $1^{\circ}$, parágrafo único). Esse decreto sucedeu regulamentações prévias congêneres, aprovadas também após 1988. Para um histórico da legislação que regulamenta o MRE, de 1808 até 1979, ver Castro (1983). Para a regulamentação mais recente do MRE, ver o portal eletrônico da Presidência da República (http:// www.planalto.gov.br).

23 No caso específico da declaração de guerra, a Constituição de 1988 exclui a competência atribuída ao Presidente da República para a direção (toda responsabilidade no encaminhamento e êxito) da guerra, constante da Constituição de 1967 (art. 92, § 2º ). A Constituição de 1967 “elimina o restritivo 'política' na direção da guerra pelo Presidente da República $\left(\S 2^{\circ}\right)$, que vem da Constituição de 1934 (art. 160), mantido pela de 1946 (art. 178), com o que the atribui toda a responsabilidade no encaminhamento da guerra e em seu êxito" (JACQUES, 1967, p. 97).

24 Ainda sobre o tema, o Conselho Nacional de Defesa, presente sob diferentes nomenclaturas nas constituições brasileiras desde 1934, é tido, na Constituição de 1988, como órgão de consulta do Presidente sobre as hipóteses de declaração de guerra e de celebração da paz (art. 91, § $1^{\circ}$, I). Nesse sentido, a Constituição de 1967, no caso específico de estudos, formulação e condução da segurança nacional (incluindo declaração de guerra e celebração da paz), traz a competência de assessoria do Conselho de Segurança Nacional (arts. 90-91). "que acarretem encargos ou compromissos gravosos ao patrimônio nacional" 25 (art. 49, I, da CF-1988); referendar a celebração de tratados pelo Presidente da República (art. 84, VIII, da CF1988; art. 83, VIII, da CF-1967) e autorizar ou referendar a decisão do Presidente de declarar a guerra e celebrar a paz (arts. 84, XIX e XX, e 49, II, da CF-1988; arts. 47, II, e 83, X, da CF-1967).

Ainda relativo ao poder Legislativo, em ambas as Constituições, foi atribuída ao Senado Federal a competência para aprovar, por meio de sabatina, a "escolha dos chefes de missão diplomática permanente", ou seja, os titulares das embaixadas brasileiras (art. 52, IV, da CF-1988 e art. 45, I, da CF-1967).

Além dos poderes Executivo e Legislativo, o poder Judiciário também tem competência constitucional para atuar em momentos da política externa. Ao Supremo Tribunal Federal (STF) compete, por exemplo, processar e julgar litígio entre Estado estrangeiro ou organismo internacional e o Brasil (União, estados, Distrito Federal ou territórios) (art. 102, I, da CF-1988; art. 114, I, da CF-1967) ${ }^{26}$ e julgar decisões que declarem a inconstitucionalidade de tratados internacionais (arts. 102, III, b, e 114, III, da CF-1967). É ainda atribuída competência ao Superior Tribunal de Justiça (STJ) para julgar decisões que contrariem tratado internacional - uma inovação da Constituição de 1988 (art. 105, III, a) ${ }^{27}$. À Justiça Fe-

25 Essa restrição não estava presente nas constituições anteriores.

26 De acordo com a teoria do ius imperii, estão submetidos à apreciação do poder Judiciário de um Estado apenas os atos de natureza privada dos demais. Para aplicação de tal teoria pelo poder Judiciário brasileiro, ver, por exemplo, Brasil. Tribunal Superior do Trabalho (1994) e Brasil. Supremo Tribunal Federal (2002).

27 O STJ foi criado somente na Constituição de 1988 e passou a dividir a competência para avaliação de tratados com o STF. Enquanto este avalia a inconstitucionalidade de tratados internacionais, o STJ decide os litígios quando uma lei ordinária está em questão. Ainda sobre a competência do STJ em política externa, cabe apontar a federalização dos crimes contra os direitos humanos, em que o Procurador-Geral da República, em cumprimento das obrigações decorrentes de tratados internacionais de direitos humanos, dos quais o Brasil seja parte, pode suscitar o STJ para o deslocamento de casos da justiça comum para a Justiça Federal (cf. BRASIL. PRESIDÊNCIA DA REPÚBLICA. CASA CIVIL, 2004b). 
deral compete julgar as causas fundadas em tratados internacionais (art. 109, III, da CF-1988; art. 119 da CF-1967).

Após a descrição dos dispositivos constitucionais que estabelecem a distribuição de competências entre os poderes Executivo, Legislativo e Judiciário, passamos a seguir a avaliar o papel de cada um deles no que se refere à política externa.

Observa-se que, tanto na Constituição de 1967 quanto na de 1988, o poder Executivo, em comparação com os demais poderes, tem um papel eminentemente concentrado nas fases de formulação e decisão da política externa. Essa concentração é mais evidente quando se trata da declaração de guerra e da celebração da paz, temática por cuja implementação esse poder também é responsável (em ambas as Constituições). Destacase, ainda, que no caso da Constituição de 1967 , especificamente, o poder Executivo também atuava na avaliação da guerra ${ }^{28}$. Conclui-se, portanto, que as competências do poder Executivo em ambas as Constituições não foram modificadas na sua essência, exceto quanto à avaliação de questões relativas à guerra (fase para a qual não há previsão na Constituição vigente).

O poder Legislativo, por sua vez, assume um papel preponderante de "co-decisor", em ambas as Constituições, como responsável pela aprovação das decisões do poder Executivo sobre celebração de $\operatorname{tratados}^{29}$, declaração de guerra e celebração da paz. Ademais, desempenha função na fase de formulação da política para manter relações com outros Estados e participar de organizações internacionais ${ }^{30}$. Ressalta-se que, em nenhuma das temáticas analisadas, foi atribuída com-

\footnotetext{
28 Ver nota de rodapé anterior.

29 Especificamente, na incorporação de tratados de direitos humanos, a partir da Emenda Constitucional n. 45/ 2004, o poder Legislativo passou a ter a prerrogativa de determinar o seu status jurídico no ordenamento interno, de acordo com o quorum de aprovação que tenha alcançado $\left(\operatorname{art.} 5^{\circ}, \S 3^{\circ}\right)$. Entende-se que esse é um papel de co-decisão no processo da política externa.
}

30 O Senado Federal, ao aprovar, por meio de sabatina, os titulares das embaixadas brasileiras (art. 52, IV, CF-1988; art. 45, I, da CF-1967), participa em certa medida na formulação da política externa. Vale ressaltar que as relações diplomáticas deram-se, por muito tempo, principalmente por meio das representações diplomáticas em outros países. Esse contexto mudou e já foi tematizado em proposta de emenda constitucional (Proposta de Emenda Constitu- petência para as fases de implementação ${ }^{31}$ e avaliação ao Legislativo.

No que se refere ao poder Judiciário, nos dois períodos analisados, verifica-se possibilidade de sua participação, mediante provocação ad hoc, nas fases de implementação e avaliação de tratados ${ }^{32}$. De uma constituição para outra, verificou-se apenas uma modificação na distribuição de competências no âmbito interno do poder Judiciário, isto é, o que antes estava concentrado no STF passou a ser compartilhado por este com o $\mathrm{STJ}^{33}$. A partir de 1988, o poder Judiciário pode ser provocado para avaliação da política para manter relações com outros Estados e participar de organizações internacionais. Em nenhuma das Constituições analisadas, no entanto, foi atribuída competência ao poder Judiciário para atuar nas fases da política de declaração de guerra e celebração da paz.

Como observações gerais sobre a distribuição de competências, tanto na Constituição de 1967 como na de 1988, tem-se que: o poder Executivo ainda guarda papel central na formulação e na decisão da política externa; o poder Legislativo atua preponderantemente no processo de (co)decisão a posteriori e o poder Judiciário, em eventual participação ad hoc.

cional (PEC) n. 387/2001 ou PEC n. 20/2003), que procurava trazer à competência do Senado a sabatina dos negociadores comerciais brasileiros que integram as delegações, independentemente de serem titulares de embaixadas. Entende-se que o dispositivo em vigor, assim como a proposta de emenda, procuram ampliar o papel de co-decisor (para também a nomeação dos representantes) e, dessa forma, aumentar o grau de influência do Senado na formulação da política externa.

31 Salvo se a regulamentação infraconstitucional da internalização de tratados for considerada implementação.

32 Explicita-se que são considerados como participação na fase de implementação os atos relativos à interpretação de conteúdo de tratado incorporado ao ordenamento interno - o que, a partir da Constituição de 1988, passou a ser desempenhado pelo STJ. A avaliação, por sua vez, consiste no conhecimento das ações de inconstitucionalidade (pelo STF).

33 A respeito da criação do STJ, v. nota de rodapé 30. Observa-se que a Emenda Constitucional n. 45/2004 - sobre a federalização dos crimes contra os direitos humanos veio a reforçar a perspectiva de participação do poder Judiciário na fase de implementação de tratados, dado que o deslocamento de competência, de violações graves aos direitos humanos, das justiças estaduais para o STJ procura favorecer a implementação daqueles tratados. 
Torna-se importante, no entanto, contextualizar, que a distribuição de competências para a condução da política externa (inclusive), a partir Constituição de 1988 está sob égide do artigo $4^{\circ}$ que estabelece os princípios que devem reger as relações internacionais do Brasil ${ }^{34}$. Essa foi uma inovação em relação às constituições brasileiras de todos os períodos anteriores. Entende-se aqui que tais princípios consagraram, no marco regulatório nacional, oportunidades de percepção sobre um adensamento da relação entre as políticas interna, externa e internacional. Princípios esses que devem tanto orientar a interpretação da distribuição de competências para política externa como a própria condução das políticas públicas.

Além disso, no tocante à distribuição de competências para a política externa, apesar das previsões específicas, de forma geral, não terem sido alteradas da Constituição de 1967 para a de 1988, é possível identificar processos de emenda constitucional desde a aprovação desta Constituição, para a redistribuição de competências ${ }^{35}$. Estimase que isso possa ser reflexo do processo de amadurecimento da redemocratização no Brasil, em convergência com a percepção pelo poder Público de um claro adensamento da relação de continuum entre as políticas interna, externa e internacional ${ }^{36}$ - o que pode até mesmo favorecer a

\footnotetext{
34 Ver extrato deste artigo no Anexo.

35 O pano de fundo das PECs é a revisão da relação entre os poderes Executivo e Legislativo quanto à condução da política externa. As PECs podem ser agrupadas em torno das seguintes demandas: aumentar o campo temático de controle ex post do Congresso Nacional sobre tratados e acordos internacionais; acrescentar a competência de alterar, emendar, fazer reservas, elaborar cláusulas interpretativas a tratados e acordos internacionais; instituir o mecanismo de fast track no Brasil, ou seja, autorização prévia, por parte do Congresso Nacional, para o Executivo participar de negociações internacionais; exigir do Executivo a prestação de contas e de informações sobre as negociações internacionais para que o Congresso Nacional possa ter conhecimento prévio dos tratados e acordos internacionais que serão destinados à sua apreciação; acrescentar a competência do Legislativo ser consultado também sobre a denúncia de tratados e acordos internacionais (não apenas aprovação); escolha dos negociadores internacionais, por meio de sabatina no Congresso Nacional, à semelhança do que ocorre com relação à escolha de chefes de missão diplomática permanente do Brasil em outros países. Para acesso a uma lista das PECs, cf. Inesc (2006).

36 A respeito desse adensamento, indica-se o exemplo da política comercial multilateral no âmbito da Organização
}

aplicação dos princípios do artigo $4^{\circ}$ da Constituição de 1988, mencionado acima.

\section{CONTROLE DA POLÍTICA EXTERNA NA CONSTITUIÇÃO FEDERAL DE 1988}

O objetivo desta seção consiste em examinar possíveis formas de controle sobre o poder público disponibilizadas pela Constituição Federal de 1988 para supervisão da política externa ${ }^{37}$. Como as políticas públicas, em cada uma de suas fases (formulação, decisão, implementação e avaliação), devem ser conduzidas por meio de atos e normas dos poderes competentes (em razão do princípio da legalidade), as formas de controle eleitas para análise, nesta seção, consistem no controle dos atos da administração pública ${ }^{38} \mathrm{e}$ em determinados meios de requerer publicidade na condução da política externa.

Dado o contexto de restabelecimento do regime democrático no Brasil, a regulamentação constitucional dos mecanismos de controle do poder público é de especial relevo, porque estabelece os meios de supervisão da aplicação dos princípios característicos aos sistemas democráticos, como as garantias de direitos (arts. $4^{\circ}$, II, e $5^{\circ}$ da CF1988), a publicidade dos negócios públicos (arts. $5^{\circ}$, XXXIII, e $37, \S 3^{\circ}$, II, da CF-1988) e os limites dos três poderes ${ }^{39}$.

De acordo com o artigo 70 da Constituição Federal, as formas de controle dos atos da admi-

Mundial do Comércio (que também proporcionou as propostas apresentadas pelas PCEs indicadas em nota de rodapé supra): "[...] três pontos devem ser destacados sobre a regulamentação do sistema multilateral de comércio pós-1994: (i) não corresponde apenas a um acordo sobre tarifas e comércio; (ii) regula áreas não apenas do comércio stricto sensu, mas também áreas relacionadas ao comércio e (iii) regula áreas fortemente relacionadas à política pública dos membros" (SANCHES, 2004, p. 69). Cf. também Ostry (2000).

37 Atente-se que, embora a distribuição de competências entre os Poderes também possa ser analisada como uma forma de controle, a seção anterior não teve por escopo tal análise.

38 Nota-se, entretanto, que os meios de controle dos atos administrativos não são elementos únicos e suficientes para dar conta da totalidade das políticas públicas. Para análise da relação entre direito administrativo e políticas públicas, ver Bucci (2002).

39 Cf. Bieber (1990, p. 148-173), que parte do conceito de controle em âmbito nacional para transpô-lo para o comunitário. 
nistração pública abrangem a análise dos parâmetros orçamentários, fiscais e programáticos e podem ser classificadas como internas e externas (cf. PIETRO, 2006, p. 693 ss.). O controle interno (para avaliação de seus próprios atos) é exercido dentro de cada um dos poderes por meios administrativos ex officio ou mediante provocação por indivíduo que apresente petição ${ }^{40}$. Como tal controle é definido por regulamentação própria, sua análise foge do escopo deste artigo, qual seja, a análise da regulamentação constitucional. O controle externo, por sua vez, consiste na fiscalização dos atos pelo poder Legislativo que, no caso da União, é o Congresso Nacional ${ }^{41}$.

Esse controle é realizado tendo em vista (i) os princípios que regem a administração pública em geral estabelecidos pelo artigo 37 da Constituição de 1988 (tal como modificado pela Emenda Constitucional n. 19/1998) - legalidade, impessoalidade, moralidade, publicidade e eficiência - e (ii) as previsões contidas no Plano Plurianual (PPA) ${ }^{42}$, na Lei de Diretrizes Orçamentárias (LDO) ${ }^{43}$ e na Lei Orçamentária Anual (LOA) ${ }^{44}$ referentes ao período em discussão. Isso porque a Constituição veda o início de projetos ou programas não incluídos na LOA (art. 167, I) e a realização de despesas ou

40 De acordo com o Art. 50, XXXIV, a, da CF-1988, o direito de petição aos poderes públicos em defesa de direitos ou contra ilegalidade ou abuso de poder é assegurado a todos, independentemente do pagamento de taxas.

41 O poder Legislativo exerce essa função com o auxílio do Tribunal de Contas da União (TCU), para a análise orçamentária. Sua competência é determinada, expressamente, pelo art. 49, X, da CF-1988, com relação aos atos do poder Executivo.

42 O PPA (art. 165, $\S 1^{\circ}$ ) é uma lei de periodicidade quadrienal, instituída pela Constituição Federal de 1988, como instrumento normatizador do planejamento de médio prazo e de definição das macro-orientações do Governo Federal para a ação nacional em cada período de quatro anos, sendo estas determinantes, ou seja, mandatórias, para o setor público e indicativas para o setor privado (art. 174 da Constituição).

43 A LDO (art. 165, § 2 $2^{\circ}, \mathrm{CF}-1988$ ) tem peridiocidade anual e destina-se a estabelecer parâmetros para a forma e o conteúdo com que a lei orçamentária de cada exercício deve apresentar-se e a indicar as prioridades a serem observadas em sua elaboração.

44 A LOA (art. 165, § 5º, CF-1988) é a lei que prevê os orçamentos fiscal, de investimentos e seguridade social para o exercício subseqüente àquele em que é adotada. assunção de obrigações diretas que excedam os créditos orçamentários ou adicionais (art. 167, II) ${ }^{45}$.

A utilização deste tipo de controle sobre a política externa, mediate adequada transposição dos princípios do artigo 37, por exemplo, é questão que fica aberta. Por outro lado, o controle dos atos administrativos a partir de princípios pode ser um modelo para o controle da política externa, inclusive a partir dos princípios arrolados no artigo $4^{\circ}$ da Constituição Federal (princípios que regem as relações internacionais).

Além disso, a prática demonstra que os projetos do Ministério das Relações Exteriores (MRE) são incluídos nas leis orçamentárias da União sob rubricas genéricas, de modo que a possibilidade de sua fiscalização torna-se precária ${ }^{46}$. Especulase que o pouco interesse do poder Legislativo sobre o controle orçamentário do MRE dá-se em razão do baixo volume de recursos destinados a este Ministério no orçamento geral ${ }^{47}$.

45 Aliada à idéia de isolamento da política externa, outro argumento utilizado, no mesmo sentido, tem sido o fato de a política externa ser uma política de meios e não de fins. Reitera-se, aqui, as hipóteses de modificação do caráter da regulamentação internacional e do continuum entre as políticas interna, externa e internacional.

$46 \mathrm{Na}$ LOA referente a 2006, por exemplo, o maior volume de recursos destinados ao MRE (R\$ 561548 979,00 dos R\$ 1578789 657,00) era alocado sob a rubrica "Administração da Unidade - Nacional” (BRASIL. PRESIDÊNCIA DA REPÚBLICA. CASA CIVIL, 2006). Em nenhum dos 24 desafios identificados pela LDO referente a 2006 (BRASIL. PRESIDÊNCIA DA REPÚBLICA. CASA CIVIL, 2005) foram estabelecidas metas-síntese que pudessem ser alcançadas por meio da política externa. Isso é verdade até mesmo para o desafio n. 15, que se refere, expressamente, ao plano internacional, qual seja, promover os valores e os interesses nacionais e intensificar o compromisso do Brasil com uma cultura de paz, solidariedade e de direitos humanos no cenário internacional. O meio identificado para superação de tal desafio consiste na implantação da infraestrutura necessária para a realização dos Jogos Panamericanos e do programa "Brasil no Esporte de Alto Rendimento". Não houve estipulação de recursos nem mesmo para as iniciativas do Mercosul, com exceção daqueles direcionados para as estradas nacionais que fazem parte do "Corredor Mercosul" (no âmbito do desafio n. 8).

47 Conforme a LOA referente a 2006 (BRASIL. PRESIDÊNCIA DA REPÚBLICA. CASA CIVIL, 2006), o volume total de recursos destinados ao MRE soma R\$ 1584 183 222,00, em comparação, por exemplo, aos R\$ 5408 043 973,00 alocados para o Ministério da Agricultura, Pe- 
Além dos mecanismos previstos pelo artigo 70 da Constituição Federal vigente, o poder Legislativo dispõe de outros meios para supervisionar as atividades do Executivo. Dentre as alternativas disponíveis, há de se citar, por exemplo, o mecanismo previsto pelo artigo 50 da Constituição Federal, o qual estatui que a Câmara dos Deputados e o Senado Federal, ou mesmo suas Comissões $^{48}$, podem convocar ministros de Estado ou quaisquer titulares de órgãos diretamente subordinados à Presidência da República para prestarem, pessoalmente, informações sobre assunto previamente determinado, importando crime de responsabilidade a ausência sem justificação adequada. De acordo com o parágrafo $2^{\circ}$ do mesmo artigo, as Mesas da Câmara dos Deputados e do Senado Federal também podem encaminhar pedidos escritos de informações a ministros de Estado ou a qualquer das pessoas referidas no caput do artigo; neste caso, a recusa de prestar informações, o não atendimento do pedido, no prazo previsto, ou a prestação de informações falsas configuram crime de responsabilidade ${ }^{49}$. Ainda com relação a audiências, as Comissões podem convidar ministros e outras autoridades a comparecem (art. 58, § 2 ${ }^{\circ}$, III e V, CF-1988), embora sua presença não seja obrigatória ${ }^{50}$. Observa-se que, nestas audiências, é possível a participação de entidades da sociedade civil (o art. $58, \S 2^{\circ}$, II).

cuária e Abastecimento (MAPA), aos R\$ 5104576 399,00, do Ministério da Justiça e, principalmente, aos R\$ 276456 627594,00 , reservados para o pagamento de encargos financeiros da União.

48 As comissões mais relevantes para o tema de política externa são: no Congresso Nacional, a Comissão Parlamentar Conjunta do Mercosul (CPCM); no Senado, a Comissão de Relações Exteriores e Defesa Nacional (CRE); na Câmara dos Deputados, a Comissão de Relações Exteriores e de Defesa Nacional (CREDN).

49 A Constituição também faculta aos ministros de Estado comparecer, sponte sua e mediante entendimentos com a Mesa respectiva, ao Senado Federal, à Câmara dos Deputados ou a qualquer de suas Comissões, para expor assunto de relevância de seu Ministério.

50 De fato, a partir de simples pesquisa realizada sobre as informações disponíveis na página eletrônica do Congresso, verifica-se que é elevado o número de convites apresentados pelas Comissões aos Ministros. Tais convites, contudo, raramente são atendidos. As razões das recusas e dos não comparecimentos, contudo, não podem ser acessadas na mesma página.
Estes meios, contudo, não determinam nenhum tipo de modificação ou sujeição do ministro às deliberações do Congresso. Seu objetivo preponderante consiste em impor, pelo menos, algum grau de publicidade na condução da política externa pelos órgãos competentes.

Embora teoricamente seja possível a apropriação de meios de controles internos para controle da política externa, verifica-se que, a partir dos dois exemplos de controle apresentados, parece ser essencial a identificação de outros elementos que auxiliem na verificação das hipóteses normativas apresentadas na primeira seção deste artigo. Dentre tais elementos, citam-se: regulamentação infraconstitucional relativa a formas de controle interno; e dados empíricos sobre as formas de controle de políticas que têm sido utilizadas, a partir da entrada em vigência da Constituição Federal de 1988.

Atenta-se, ainda, para o fato de que outras formas de controle ainda podem ser exploradas na Constituição, como o recurso ao poder Judiciário e exploração da competência das Comissões das Casas do Congresso Nacional para apreciação dos planos de desenvolvimento nacional, dentre outros (art. 58, § $2^{\circ}, \mathrm{VI}$ ).

\section{CONSIDERAÇÕES FINAIS}

Após a análise comparativa apresentada neste artigo, é possível observar que a regulamentação das competências para a política externa não sofreu alterações significativas entre a Constituição de 1967 e a de 1988, apesar de os dois períodos constitucionais serem sensivelmente distintos quanto ao seus contextos históricos e políticos.

Esta assertiva foi possibilitada pela utilização da metodologia das fases das políticas públicas, cujo resultado foi consubstanciado no quadro apresentado na segunda seção deste artigo. A partir deste quadro, pode-se, ainda, explorar qual a regulamentação ideal da distribuição de competências, num regime democrático, para promover um quadro regulatório que reflita a concepção de política externa como política pública e, assim, atender à demanda por revisão das políticas como um continuum. Isso significa que os momentos da política externa podem ser afetados tanto pelas categorias das políticas públicas quanto pelas da política internacional. Ademais, uma passa a influenciar a outra, permitindo, assim, a revisão de seus momentos. 
Foram identificadas, porém, tentativas isoladas de emenda constitucional no tocante à (re)distribuição de competências que tiveram início após a entrada em vigor da atual Constituição. Embora isso possa ser indicado como reflexo do processo de amadurecimento da redemocratização no Brasil, pode-se questionar se as PECs adotam uma perspectiva de política externa congruente com o conceito de política pública num Estado Democrático de Direito.

Além disso, questiona-se também o quanto tais propostas levam em consideração sua implicação para a regulamentação da política externa como um todo e, até mesmo, sua coerência com o regime democrático em que vigorarão. Isso porque, como demonstrou a análise apresentada na seção II, a regulamentação constitucional das competências relativas à política externa, nos períodos comparados, atende tanto a regime autoritário quanto ao democrático.
A grande mudança significativa observada na Constituição de 1988 foi a inclusão dos princípios que devem nortear as relações internacionais (art. $4^{\circ}$ ), embora ainda não haja uma prática de utilizálos como forma de controle, por meio do conteúdo da política externa brasileira ${ }^{51}$.

Por fim, observou-se também que não foi possível identificar formas explícitas de controle sobre a política externa, na Constituição de 1988 . Fator que poderia ser o diferencial neste contexto. Deixa-se a ressalva de que este último ponto merece ser complementado com outras pesquisas (especialmente de regulamentação infraconstitucional e empírica), como indicado na seção III.

\footnotetext{
51 Uma tentativa de associar tais princípios ao controle da política externa foi feita no Informe n. 1 do Programa de Acompanhamento da Política Externa em Direitos Humanos (Papedh) (PAPEDH, 2005, p. 21).
}

Michelle Ratton Sanchez (mratton@fgvsp.br) é doutora em Filosofia e Teoria Geral do Direito pela Universidade de São Paulo (USP), Professora da Escola de Direito de São Paulo da Fundação Getúlio Vargas (FGV) e pesquisadora do Núcleo de Direito e Democracia do Centro Brasileiro de Análise e Planejamento (NDD-CEBRAP).

Elaini C. G. da Silva (elaini@gmail.com) é mestranda em Direito Internacional na Universidade de São Paulo (USP) e pesquisadora da Escola de Direito de São Paulo da Fundação Getúlio Vargas (FGV) e do Instituto de Direito de Comércio Internacional e Desenvolvimento (IDCID).

Evorah L. Cardoso (evorahl@gmail.com) é mestranda em Filosofia e Teoria Geral do Direito na Universidade de São Paulo (USP), bolsista da Fundação de Amparo à Pesquisa do Estado de São Paulo (FAPESP) e pesquisadora do Núcleo de Direito e Democracia do Centro Brasileiro de Análise e Planejamento (NDD-CEBRAP).

Priscila Spécie (prispecie@yahoo.com.br) é mestranda em Ciência Política na Universidade de São Paulo (USP) e pesquisadora da Escola de Direito de São Paulo da Fundação Getúlio Vargas (FGV) e do Núcleo de Direito e Democracia do Centro Brasileiro de Análise e Planejamento (NDD-CEBRAP).

\section{REFERÊNCIAS BIBLIOGRÁFICAS}

ARON, R. 2002. Paz e guerra entre as nações. Brasília: UNB.

BIEBER, R. 1990. Democratic Control of European Foreign Policy. European Journal of International Law, New York, v. 1, n. 1-2, p. 148-173.

BUCCI, M. P. D. 2002. Direito Administrativo e políticas públicas. São Paulo: Saraiva.

CASTRO, F. M. O. 1983. História da organiza- ção do Ministério das Relações Exteriores. Brasília: UNB.

COUTO, C. G. 2005. Constituição, competição e políticas públicas. Lua Nova, São Paulo, v. 65, p. $95-135$.

COUTO, E. F. 2004. Judicialização da política externa e direitos humanos. Revista Brasileira de Política Internacional, Brasília, v. 47, n. 1, p. 140-161. 
PIETRO, M. S. Z. 2006. Direito Administrativo. São Paulo: Atlas.

FONSECA JÚNIOR, G. 1998. A legitimidade e outras questões internacionais: poder e ética entre as nações. $2^{\mathrm{a}}$ ed. São Paulo: Paz e Terra.

INESC. 2006. Congresso Nacional: mapeamento de propostas com escopo internacional em tramitação. Brasília: Instituto de Estudos Socioeconômicos. Disponível em: http:// www.inesc.org.br/pt/publicacoes/textos/ texto.php?oid=5MsfcbeFuaPNrI7VGDQz DwPHGkwoJpVE. Acesso em: 30.jul.2006.

INGRAM, H. M. \& FIEDERLEIN, S. L. 1998. Traversing Boundaries: A Public Policy Approach to the Analysis of Foreign Policy. The Western Political Quarterly, New York, v. 41, n. 4, p. 725-745, Dec.

JACQUES, P. 2000. 1967. A constituição do Brasil explicada. Rio de Janeiro: Forense.

KEOHANE, R. O. \& NYE, J. S. 2000. Power and Interdependence. $3^{\text {rd }}$ ed. New York: Longman.

.2000. Globalization: What's New? What's Not? (and So What?). Foreign Policy, Washington, D. C., n. 118, p. 104-119, Spring.

LACERDA, G. B. 2001. Identidade (inter)nacional e política externa do Brasil. Revista de Sociologia e Política, Curitiba, n.17, p. 147-150.

LAFER, C. 2004. A identidade internacional do Brasil e a política externa brasileira. $2^{\mathrm{a}}$ ed. São Paulo: Perspectiva.

LENTNER, H. H. 2006. Public Policy and Foreign Policy: Divergences, Intersections, Exchange. Review of Policy Research, London, v. 23, n. 1, p. 169-181, Jan.

LIMA, M. R. S. 2002. Foreign Policy and Democracy: A Preliminary Analysis of the Brazilian Case. Trabalho apresentado na Convenção anual da Associação Internacional de Sociologia, realizada em Nova Orleans, de 24 a 27 de março. Disponível em: http:// www.isanet.org/noarchive/lima.html. Acesso em: 28.ago.2006.
. Instituições democráticas e política exterior. Contexto Internacional, Rio de Janeiro, v. 22 , n. 2, p. 265-303, jul.-dez.

LULA DA SILVA, L. I. \& BLAIR, T. 2006. Uma visão compartilhada. Folha de São Paulo, p. A3, 9.mar.

MERLE, M. 1998. La politique étrangère. Paris : PUF.

MILNER, H. 1997. Interest, Institutions and Information: Domestic Politics and International Relations. Princenton: Princeton University.

MULLER, P. 1990. Les politiques publiques. $4^{\mathrm{e}}$ ed. Collection « Que sais-je? ». Paris: PUF.

OSTRY, S. 2000. WTO: Institutional Design for Better Governance. Trabalho apresentado no seminário "Efficiency, Equity and Legitimacy: The Multilateral Trading System at the Millennium", realizado na J. F. Kennedy School of Government, em Boston, entre 2 e 3 de junho. Disponível em: http://www.utoronto.ca/ cis/ostry.html. Acesso em: 10.jun.2002.

PAPEDH. 2005. Política externa e direitos humanos: o Brasil na Comissão de Direitos $\mathrm{Hu}-$ manos da ONU. Informe n. 1. Brasília: Programa de Acompanhamento de Política Externa em Direitos Humanos. Disponível em: www2.camara.gov.br/comissoes/cdhm/ relatorios/papedh. Acesso em: 15.set.2006.

SANCHEZ, M. R. 2004. Demandas por um novo arcabouço sócio-jurídico na Organização Mundial do Comércio e o caso do Brasil. São Paulo. Tese (Doutorado em Filosofia e Teoria Geral do Direito). Universidade de São Paulo.

.2006. Política externa como política pública: uma análise pela regulamentação constitucional brasileira. São Paulo: USP.

SILVA, J. A. 1998. Curso de Direito Constitucional. $15^{\mathrm{a}}$ ed. São Paulo: Malheiros.

VARGAS, C. S. 1992. Las políticas públicas: nueva perspectiva de analisis. Universitas, $\mathrm{n}$. 83 , p. $35-100$, nov. 


\section{OUTRAS FONTES}

BRASIL. PRESIDÊNCIA DA REPÚBLICA. CASA CIVIL. 2004a. Decreto n. 5 024, de 5 de abril. Aprova a Estrutura Regimental e o Quadro Demonstrativo dos Cargos em Comissão e das Funções Gratificadas do Ministério das Relações Exteriores, e dá outras providências. Diário Oficial da União, Brasília, 6.abr., p. 1. Disponível em: http:// www.planalto.gov.br/ccivil_03/_Ato20042006/2004/Decreto/D5032impressao.htm. Acesso em: 15.dez.2006.

2004b. Emenda constitucional n. 45, de 30 de dezembro. Altera dispositivos dos arts. $5^{\circ}, 36,52,92,93,95,98,99,102,103,104$, $105,107,109,111,112,114,115,125,126$, $127,128,129,134$ e 168 da Constituição Federal, e acrescenta os arts. 103-A, 103B, 111A e 130-A, e dá outras providências. Diário Oficial da União, Brasília, 31.dez., p. 9. Disponível em: https://www.planalto.gov.br/ ccivil_03/Constituicao/Emendas/Emc/ emc45.htm. Acesso em: 15.dez.2006.
2005. Lei n. 11 178, de 21 de setembro. Dispõe sobre as diretrizes para a elaboração da lei orçamentária de 2006 e dá outras providências. Diário Oficial da União, Brasília, 22.set., p. 1 (edição extra). Disponível em: http:/ /www.planalto.gov.br/ccivil_03/_Ato20042006/2005/Lei/L11178.htm. Acesso em: 15.dez.2006.

2006. Lei n. 11 306, de 16 de maio. Estima a receita e fixa a despesa da União para o exercício financeiro de 2006. Diário Oficial da União, Brasília, 17.maio, p. 1. Disponível em: http://www.planalto.gov.br/ccivil_03/ _Ato2004-2006/2006/Lei/L11306.htm. Acesso em: 15.dez.2006.

BRASIL. SUPREMO TRIBUNAL FEDERAL. 2002. AReg-RE-222.368-4. Disponível em: http://www.stf.gov.br. Acesso em: 26.set.2006.

BRASIL. TRIBUNAL SUPERIOR DO TRABALHO. 1994. RR-107.679/94.9. Disponível em: http://www.tst.gov.br. Acesso em: 26.set.2006. 
ANEXO - DISPOSITIVOS CONSTITUCIONAIS CITADOS NO ARTIGO

\title{
CONSTITUIÇÃO DE 1967 (INCLUI MUDANÇAS DA EMENDA CONSTITUCIONAL N. 1 DE 1969)
}

\author{
Art. $8^{\circ} \quad$ Compete à União: \\ I manter relações com Estados estrangeiros e com eles celebrar tratados e convenções; \\ participar de organizações internacionais; \\ II declarar guerra e fazer a paz. \\ Art. 40 Os Ministros de Estado são obrigados a comparecer perante a Câmara dos Deputados e o \\ Senado Federal ou qualquer de suas Comissões, quando uma ou outra Câmara os convo- \\ car para, pessoalmente, prestar informações acerca de assunto previamente determinado. \\ $\S 1^{\circ} \quad$ A falta de comparecimento, sem justificação, importa em crime de responsabilidade. \\ $\S 2^{\circ} \quad$ Os Ministros de Estado, a seu pedido, poderão comparecer perante as Comissões ou o \\ Plenário de qualquer das Casas do Congresso Nacional e discutir projetos relacionados \\ com o Ministério sob sua direção.
}

Art. 45 Compete ainda privativamente, ao Senado:

I aprovar, previamente, por voto secreto, a escolha de magistrados, quando exigido pela Constituição; do Procurador-Geral da República, dos Ministros do Tribunal de Contas, do Prefeito do Distrito Federal, dos Governadores dos Territórios, dos Chefes de Missão Diplomática de caráter permanente quando determinado em lei, e de outros servidores.

Art. 47 É da competência exclusiva do Congresso Nacional [equivale ao art. 44, a partir da EC 1 de 1969]:

I resolver definitivamente sobre os tratados celebrados pelo Presidente da República;

II autorizar o Presidente da República a declarar guerra e a fazer a paz; a permitir que forças estrangeiras transitem pelo território nacional ou nele permaneçam temporariamente, nos casos previstos em lei complementar.

Art. 83 Compete privativamente ao Presidente [equivale ao art. 81 da EC 1 de 1969]:

VII manter relações com Estados estrangeiros [equivale ao art. 81, IX da EC 1 de 1969];

VIII celebrar tratados, convenções e atos internacionais, ad referendum do Congresso Nacional [ref. art. 81, X da EC 1 de 1969];

IX declarar guerra, depois de autoriza do pelo Congresso Nacional, ou sem esta autorização, no caso de agressão estrangeira verificada no intervalo das sessões legislativas [cf. art. 81, XI da EC 1 de 1969];

X fazer a paz, com autorização ou ad referendum do Congresso Nacional [equivale ao art. 81, XII da EC 1 de 1969].

Art. 90 O Conselho de Segurança Nacional destina-se a assessorar o Presidente da República na formulação e na conduta da segurança nacional. $\S 1^{\circ}$ - O Conselho compõe-se do Presidente e do Vice-Presidente da República e de todos os Ministros de Estado.

[Texto modificado a partir da EC 1 de 1969: “Art. 87. O Conselho de Segurança Nacional é o órgão de mais alto nível na assessoria direta ao Presidente da República, para formulação e execução da política de segurança nacional. Art. 88. O Conselho de Segurança Nacional é presidido pelo Presidente da República e ode participam, no caráter de membros natos, o Vice-Presidente da República e todos os Ministros de Estado. Parágrafo único. A lei regulará a sua organização, competência e funcionamento e poderá admitir outros membros natos ou eventuais"] 
Art. 91 Compete ao Conselho de Segurança Nacional [equivale ao art. 89 da EC 1 de 1969]: I - o estudo dos problemas relativos à segurança nacional, com a cooperação dos órgãos de Informação e dos incumbidos de preparar a mobilização nacional e as operações militares [equivale ao art. 89, II da EC 1 de 1969].

Art.92 As forças armadas, constituídas pela Marinha de Guerra, Exército e Aeronáutica Militar, são instituições nacionais, permanentes e regulares, organizadas com base na hierarquia e na disciplina, sob a autoridade suprema do Presidente da República e dentro dos limites da lei [equivale ao art. 90 da EC 1 de 1969].

$\S 2^{\circ} \quad$ Cabe ao Presidente da República a direção da guerra e a escolha dos ComandantesChefes. [equivale ao parágrafo único do art. 91 da EC 1 de 1969]

[EC de 1969: Art. 91. As Forças Armadas, essenciais à execução da política de segurança nacional, destinam-se à defesa da Pátria e à garantia dos poderes constituídos, da lei e da ordem. Parágrafo único. Cabe ao Presidente da República a direção da política da guerra e a escolha dos Comandantes-Chefes]

Art. 114 Compete ao Supremo Tribunal Federal [art. 119 da EC 1 de 1969]:

III julgar mediante recurso extraordinário as causas decididas em única ou última instância por outros Tribunais ou Juízes, quando a decisão recorrida [equivale ao art. 119, III da EC 1 de 1969]:

a) contrariar dispositivo desta Constituição ou negar vigência de tratado ou lei federal [equivale ao art. 119, III, a da EC 1 de 1969];

b) declarar a inconstitucionalidade de tratado ou lei federal [art. 119, III, b da EC 1 de 1969].

Art. 119 Aos Juizes Federais compete processar e julgar, em primeira instância [equivale ao art. 125 da EC 1 de 1969]:

III as causas fundadas em tratado ou em contrato da União com Estado estrangeiro ou organismo internacional [equivale ao art. 125, III da EC 1 de 1969];

$\mathrm{V}$

os crimes previstos em tratado ou convenção internacional e os cometidos a bordo de navios ou aeronaves, ressalvada, a competência da Justiça Militar [equivale ao art. 125, V da EC de 1969]

\section{ATO INSTITUCIONAL N. 5 DE 13 DE DEZEMBRO DE 1968}

"são mantidas a constituição de 24/01/1967 e as constituições estaduais, com as modificações constantes deste ato. O Presidente da República poderá decretar o recesso do congresso nacional, das assembléias legislativas e das câmaras de vereadores, por ato complementar em estado de sitio ou fora dele, só voltando o mesmo a funcionar quando convocados pelo Presidente da República. O Presidente da República, no interesse nacional, poderá decretar a intervenção nos estados e municípios, sem as limitações previstas na constituição. Poderá suspender os direitos políticos de quaisquer cidadãos pelo prazo

Ementa de 10 anos e cassar mandatos eletivos federais, estaduais e municipais. Ficam suspensas as garantias constitucionais ou legais de vitalidade, inamovibilidade e estabilidade, bem como a de exercício em funções por prazo certo. O Presidente da República, em qualquer dos casos previstos na constituição, poderá decretar o estado de sítio e prorrogá-lo, fixando o respectivo prazo. Poderá após investigação, decretar o confisco de bens de todos quantos tenham enriquecido ilicitamente, no exercício do cargo ou função. Fica suspensa a garantia de hábeas corpus, nos casos de crimes políticos, contra a segurança nacional, a ordem econômica e social e a economia popular" (sem grifos no original). 


\section{CONSTITUIÇÃO DE 1988}

Art. $4^{\circ} \quad$ A República Federativa do Brasil rege-se nas suas relações internacionais pelos seguintes princípios:

I independência nacional;

II prevalência dos direitos humanos;

III $\quad$ autodeterminação dos povos;

IV não-intervenção;

$\mathrm{V} \quad$ igualdade entre os Estados;

VI defesa da paz;

VII Solução pacífica dos conflitos;

VIII repúdio ao terrorismo e ao racismo;

IX cooperação entre os povos para o progresso da humanidade;

X concessão de asilo político.

Par. Único A República Federativa do Brasil buscará a integração econômica, política, social e cultural dos povos da América Latina, visando à formação de uma comunidade latino-americana de nações.

Art. $5^{\circ}$ Todos são iguais perante a lei, sem distinção de qualquer natureza, garantindo-se aos brasileiros e aos estrangeiros residentes no País a inviolabilidade do direito à vida, à liberdade, à igualdade, à segurança e à propriedade, nos termos seguintes: [...]

XXXIII todos têm direito a receber dos órgãos públicos informações de seu interesse particular, ou de interesse coletivo ou geral, que serão prestadas no prazo da lei, sob pena de responsabilidade, ressalvadas aquelas cujo sigilo seja imprescindível à segurança da sociedade e do Estado;

XXXIV são a todos assegurados, independentemente do pagamento de taxas:

a) o direito de petição aos Poderes Públicos em defesa de direitos ou contra ilegalidade ou abuso de poder;

XXXV a lei não excluirá da apreciação do Poder Judiciário lesão ou ameaça a direito;

LXXIII qualquer cidadão é parte legítima para propor ação popular que vise a anular ato lesivo ao patrimônio público ou de entidade de que o Estado participe, à moralidade administrativa, ao meio ambiente e ao patrimônio histórico e cultural, ficando o autor, salvo comprovada má-fé, isento de custas judiciais e do ônus da sucumbência;

$\S 3^{\circ} \quad$ Os tratados e convenções internacionais sobre direitos humanos que forem aprovados, em cada Casa do Congresso Nacional, em dois turnos, por três quintos dos votos dos respectivos membros, serão equivalentes às emendas constitucionais. (Incluído pela Emenda Constitucional n. 45, de 2004).

Art. 21 Compete à União:

I manter relações com Estados estrangeiros e participar de organizações internacionais;

II declarar a guerra e celebrar a paz.

Art. 37 A administração pública direta e indireta de qualquer dos Poderes da União, dos Estados, do Distrito Federal e dos Municípios obedecerá aos princípios de legalidade, 
impessoalidade, moralidade, publicidade e eficiência e, também, ao seguinte:

$\S 3^{\circ} \quad$ A lei disciplinará as formas de participação do usuário na administração pública direta e indireta, regulando especialmente:

II o acesso dos usuários a registros administrativos e a informações sobre atos de governo, observado o disposto no art. $5^{\circ}$, X e XXXIII;

III a disciplina da representação contra o exercício negligente ou abusivo de cargo, emprego ou função na administração pública.

Art. 49 É da competência exclusiva do Congresso Nacional:

I resolver definitivamente sobre tratados, acordos ou atos internacionais que acarretem encargos ou compromissos gravosos ao patrimônio nacional

II autorizar o Presidente da República a declarar guerra, a celebrar a paz, a permitir que forças estrangeiras transitem pelo território nacional ou nele

X fiscalizar e controlar, diretamente, ou por qualquer de suas Casas, os atos do Poder Executivo, incluídos os da administração indireta.

Art. 50 A Câmara dos Deputados e o Senado Federal, ou qualquer de suas Comissões, poderão convocar Ministro de Estado ou quaisquer titulares de prestarem, pessoalmente, informações sobre assunto previamente determinado, importando crime de responsabilidade a ausência sem justificação adequada.

§1 $\quad$ Os Ministros de Estado poderão comparecer ao Senado Federal, à Câmara dos Deputados, ou a qualquer de suas Comissões, por sua iniciativa e mediante entendimentos com a Mesa respectiva, para expor assunto de relevância de seu Ministério.

$\S 2^{\circ} \quad$ As Mesas da Câmara dos Deputados e do Senado Federal poderão encaminhar pedidos escritos de informações a Ministros de Estado, importando em crime de responsabilidade a recusa, ou o não - atendimento, no prazo de trinta dias, bem como a prestação de informações falsas.

Art. 52 Compete privativamente ao Senado Federal:

IV aprovar previamente, por voto secreto, após argüição em sessão secreta, a escolha dos chefes de missão diplomática de caráter permanente;

X suspender a execução, no todo ou em parte, de lei declarada inconstitucional por decisão definitiva do Supremo Tribunal Federal.

Art. 58 O Congresso Nacional e suas Casas terão comissões permanentes e temporárias, constituídas na forma e com as atribuições previstas no respectivo regimento ou no ato de que resultar sua criação.

$\S 2^{\circ} \quad$ às comissões, em razão da matéria de sua competência, cabe:

II $\quad$ realizar audiências públicas com entidades da sociedade civil;

III convocar Ministros de Estado para prestar informações sobre assuntos inerentes a suas atribuições;

V solicitar depoimento de qualquer autoridade ou cidadão;

VI apreciar programas de obras, planos nacionais, regionais e setoriais de desenvolvimento e sobre eles emitir parecer.

Art. 70 A fiscalização contábil, financeira, orçamentária, operacional e patrimonial da União e das entidades da administração direta e indireta, quanto à legalidade, legitimidade, economicidade, aplicação das subvenções e renúncia de receitas, será exercida pelo Con- 
gresso Nacional, mediante controle externo, e pelo sistema de controle interno de cada Poder.

Art. 84 Compete privativamente ao Presidente da República

VII manter relações com Estados estrangeiros e acreditar seus representantes diplomáticos;

VIII celebrar tratados, convenções e atos internacionais, sujeitos a referendo do Congresso Nacional;

XIII exercer o comando supremo das Forças Armadas, nomear os Comandantes da Marinha, do Exército e da Aeronáutica, promover seus oficiais-generais e nomeá-los para os cargos que lhes são privativos;

XIX declarar guerra, no caso de agressão estrangeira, autorizado pelo Congresso Nacional ou referendado por ele, quando ocorrida no intervalo das sessões legislativas e, nas mesmas condições, decretar, total ou parcialmente, a mobilização nacional;

XX celebrar a paz, autorizado ou com o referendo do Congresso Nacional.

Art.91 O Conselho de Defesa Nacional é órgão de consulta do Presidente da República nos assuntos relacionados com a soberania nacional e a defesa do Estado democrático, e dele participam como membros natos:

$\S 1^{\circ} \quad$ Compete ao Conselho de Defesa Nacional:

I opinar nas hipóteses de declaração de guerra e de celebração da paz, nos termos desta Constituição.

Art. 102 Compete ao Supremo Tribunal Federal, precipuamente, a guarda da Constituição, cabendo-lhe:

I processar e julgar, originariamente:

e) o litígio entre Estado estrangeiro ou organismo internacional e a União, o Estado o Distrito Federal ou o Território; Estado, o Distrito Federal ou o Território;

III julgar, mediante recurso extraordinário, as causas decididas em única ou última instância, quando a decisão recorrida:

b) declarar a inconstitucionalidade de tratado ou lei federal.

Art. 105 Compete ao Superior Tribunal de Justiça:

III julgar, em recurso especial, as causas decididas, em única ou última instância, pelos Tribunais Regionais Federais ou pelos tribunais dos Estados, do Distrito Federal e Territórios, quando a decisão recorrida:

A contrariar tratado ou lei federal, ou negar-lhes vigência.

Art. 109 Aos juízes federais compete processar e julgar:

III as causas fundadas em tratado ou contrato da União com Estado estrangeiro ou organismo internacional;

V os crimes previstos em tratado ou convenção internacional, quando, iniciada a execução no País, o resultado tenha ou devesse ter ocorrido no estrangeiro, ou reciprocamente;

a) A as causas relativas a direitos humanos a que se refere o $\S 5^{\circ}$ deste artigo (Incluído pela Emenda Constitucional n. 45, de 2004)

$\S 5^{\circ} \quad$ Nas hipóteses de grave violação de direitos humanos, o Procurador-Geral da República, com a finalidade de assegurar o cumprimento de obrigações decorrentes de tratados internacionais de direitos humanos dos quais o Brasil seja parte, poderá suscitar, perante o 
Superior Tribunal de Justiça, em qualquer fase do inquérito ou processo, incidente de deslocamento de competência para a Justiça Federal. (Incluído pela Emenda Constitucional ${ }^{\circ} 45$, de 2004).

Art. 165 Leis de iniciativa do Poder Executivo estabelecerão:

I o plano plurianual;

II as diretrizes orçamentárias;

III os orçamentos anuais.

$\S 1^{\circ} \quad$ A lei que instituir o plano plurianual estabelecerá, de forma regionalizada, as diretrizes, objetivos e metas da administração pública federal para as despesas de capital e outras delas decorrentes e para as relativas aos programas de duração continuada.

$\S 2^{\circ} \quad$ A lei de diretrizes orçamentárias compreenderá as metas e prioridades da administração pública federal, incluindo as despesas de capital para o exercício financeiro subseqüente, orientará a elaboração da lei orçamentária anual, disporá sobre as alterações na legislação tributária e estabelecerá a política de aplicação das agências financeiras oficiais de fomento.

$\S 4^{\circ} \quad$ Os planos e programas nacionais, regionais e setoriais previstos nesta Constituição serão elaborados em consonância com o plano plurianual e apreciados pelo Congresso Nacional.

$\S 5^{\circ} \quad$ A lei orçamentária anual compreenderá:

I o orçamento fiscal referente aos Poderes da União, seus fundos, órgãos e entidades da administração direta e indireta, inclusive fundações instituídas e mantidas pelo Poder Público;

II o orçamento de investimento das empresas em que a União, direta ou indiretamente, detenha a maioria do capital social com direito a voto;

III o orçamento da seguridade social, abrangendo todas as entidades e órgãos a ela vinculados, da administração direta ou indireta, bem como os fundos e fundações instituídos e mantidos pelo Poder Público.

Art. 167 São vedados:

I o início de programas ou projetos não incluídos na lei orçamentária anual;

II a realização de despesas ou a assunção de obrigações diretas que excedam os créditos orçamentários ou adicionais; 